\title{
PENINGKATAN EKONOMI PENYANDANG DISABILIAS DI KABUPATEN SITUBONDO MENUJU KABUPATEN INKLUSI RAMAH DISABILITAS
}

\author{
${ }^{1}$ Moh. Idil Gufron, ${ }^{2}$ Abdur Rahman \\ 1,2 Fakultas Agaman Islam, Universitas Nurul Jadid \\ 1 aidil.piero7@gmail.com, ${ }^{1}$ rahman14041999@gmail.com
}

\begin{abstract}
ABSTACT
Disability causes poverty through a number of exclusion processes that occur in daily life such as the participation of persons with disabilities that require very little in the social and political sphere. Most have "exclusive" ownership in the midst of community life in the sense of alienating themselves in the process of community interaction. This of course is very decisive towards the development being carried out because this makes the diffable lack of access to information and communication. The lack of information and communication is of course related to the social and economic aspects of the diffable themselves, where they cannot access social networks which are very important for accessing world jobs. Social exclusion for persons with disabilities is a complex process that addresses access to cultural resources, rights, public services, and the inability to complete normal activities and social relations. This study was conducted qualitatively by using information through literature studies, and examining data disability in the Single Regional Data-Participatory Population Analysis (DTD$A K P)$. Disability data is sorted based on indicators in the DTD-AKP data collection to bring up the complete disability conditions. After observing and examining disability data, library searches containing regulations, policies and programs and other references related to disability analysis are carried out. After observing and examining disability data, library searches containing regulations, policies and programs and other references related to disability analysis are carried out. Based on Single Regional Data - Participatory Population Analysis (DTD-AKP) of Situbondo Regency.
\end{abstract}

Keywords: Economic Analysis of Disability, Disabiliti, incluson

\begin{abstract}
ABSTRAK
Difabel menyebabkan kemiskinan melalui beberapa proses eksklusi yang terjadi dalam kehidupan sehari-hari seperti partisipasi difabel yang cenderung sangat minim baik diranah sosial maupun politik. Sebagian besar difabel memiliki kecenderungan yang "eksklusif" ditengah-tengah kehidupan masyarakat dalam artian mengasingkan dirinya dalam proses interaksi masyarakat. Hal ini tentu sangat berpengaruh terhadap perkembangan dirinya karena kecenderungan ini menjadikan difabel minim akses informasi dan komunikasi. Minimnya informasi dan komunikasi tentu berpengaruh kepada keadaan sosial dan ekonomi dari difabel sendiri, dimana mereka tidak bisa membuka jaringan sosial yang sangat penting terutama untuk mengakses dunia pekerjaan. Eksklusi sosial bagi disabilitas merupakan proses yang kompleks meliputi keterbatasan dalam mengakses sumber budaya,hak,pelayanan public, serta ketidak mampuan untuk berpartisipasi dalam aktivitas dan hubungan sosial yang normal. Kajiana ini dilakukan secara kualitatif dengan menggunakan informasi melalui studi pustaka, dan telaah data disabilitas dalam Data Tunggal Daerah-Analisa Kependudukan Partisipatif (DTD-AKP). Data disabilitas dipilah berdasarkan indicator dalam pendataan DTD-AKP untuk memunculkan kondisi disabilitas secara komprehensif. Setelah melakukan pengamatan dan telaah terhadap data disabilitas, kemudian dilakukan penelusuran pustaka berupa peraturan, kebijakan, dan program serta refrensi lain yang berhubungan dengan analisis situasi disabilitas. Setelah melakukan pengamatan dan telaah terhadap data disabilitas, kemudian dilakukan penelusuran pustaka berupa peraturan, kebijakan, dan program serta refrensi lain yang berhubungan dengan
\end{abstract}


analisis situasi disabilitas. Berdasarkan Data Tunggal Daerah-Analisa Kependudukan Partisipatif (DTD-AKP) Kabupaten Situbondo.

Kata Kunci: Analisis Ekonomi Disabilitas, Penyandang Disabilitas, Inklusi

\section{PENDAHULUAN}

Disabilitas adalah setiap orang yang mengalami keterbatas fisik, intelektual, mental, dan/atau sensorik dalam jangka waktu lama, yang dalam berinteraksi dengan lingkungan dapat mengalami kesulitan untuk berpartisipasi secara penuh dan efektif dengan warga Negara lainnya berdasarkan sesamaan hak. Sejauh ini, orang-orang dengan disabilitas dihadapannya pada atu persoalan besar, yaitu stigma. Stigma yang menganggap disabilitas sebagai orang yang tidak bisa berbuat apa-apa dibanding orang non-disabilitas, bahkan cenderung diabaikan keberadaannya yang berakibatkan dengan keadaan perekonomiannya sehari-hari. Sehingga hak-hak dasar sebagai warga Negara tidak pernah perhatikan atau terpenuhi.

Akan tetapi setiap warga negara memiliki hak yang sama, peluang yang sama, dan kedudukan yang sama dihadapan hukum. Tidak hanya hak-hak warga negara normal pada umumnya, tetapi juga hak-hak untuk penyandang disabilitas. Hak-hak penyandang disabilitas meliputi aksesibilitas fisik, rehabilitasi, pendidikan, kesempatan kerja, peran serta dalam pembangunan, dan bantuan sosial. Di dalam memenuhi hak, kewajiban, dan kedudukan warga negaranya, salah satu upaya yang dilakukan pemerintah adalah dengan memberikan pelayanan publik. Pelayanan publik yang diberikan oleh pemerintah dapat berupa fisik maupun non fisik (Nuraviva, 2008)

Melihat persoalan yang dihadapi disabilitas, kemudian pemerintah Republik Indonesia menerbitkan Undang-Undang No 8 Tahun 2016 tentang penyandang Disabilitas. Undangundang ini sebagai pengganti dari undang-undang Nomor 4 Tahun 1997 tentang Penyandang Cacat, yang menggunkan pendekatan kesehatan dalam memperlakukan disabilitas, sehingga disabilitas hanya dianggap sebagai persoalan tubuh seorang penderita yang sakit dan patut di kasihani. Namun, sejak diterbitkan UU 8/2016 cara pandang itu diubah, tetapi lebih pada persoalan lingkungan dan cara pandang yang harus diubah, sehingga disabilitas bias hidup mandiri dan setara orang-orang non-disabilitas.

Dengan diterbitkannya UU 8/2016, kemudian atas inisiatif DPRD, Pemerintah kabupaten Situbondo menerbitkan Peraturan daerah nomor 3 Tahun 2018 tentang perlindungan dan pemberdayaanDisabilitas. Dalam perda 3/2018 memuat tentang 22 hak disabilitas yang harus dijamin oleh pemerintah daerah. Salah satunya ialah hak pendataan. Dimana semua disabilitas pertama berhak didata dalam setiap kegiatan pendaftaran penduduk dan pencatatan sipil, kedua memiliki dokumen kependudukan, dan ketiga mendapat kartu disabilitas. Hak pendataan merupakan salah satu hak dasar yang harus dipenuhi oleh pemerintah, sehingga semua disabilitas bias memiliki dokumen kependudukan atau kartu disabilitas. Karena melalui kepemilikan dokumen, makan akan memudahkan disabilitas untuk mengakses jaminan perlindungan social, kesehatan, pendidikan, pekerjaan, dan hak lainnya, sehingga mereka bias hidup serta dan bermartabat dalam kehidupan bermasyrakat.

Difabel menyebabkan kemiskinan melalui beberapa proses eksklusi yang terjadi dalam kehidupan sehari-hari seperti partisipasi difabel yang cenderung sangat minim baik diranah sosial maupun politik. Sebagian besar difabel memiliki kecenderungan yang "eksklusif" ditengah-tengah kehidupan masyarakat dalam artian mengasingkan dirinya dalam proses interaksi masyarakat. Hal ini tentu sangat berpengaruh terhadap perkembangan dirinya karena kecenderungan ini menjadikan difabel minim akses informasi dan komunikasi. Minimnya informasi dan komunikasi tentu berpengaruh kepada keadaan sosial dan ekonomi dari difabel sendiri, dimana mereka tidak bisa membuka jaringan sosial (social networking) yang sangat penting terutama untuk mengakses dunia pekerjaan (Setyaningsih \& Gutama, 2016).

Penyandang disablitas juga merupakan bagian dalam masyarakat yang berhak mendapatkan pekerjaan sesuai dengan tingkat kecacatannya, Bahkan Pasal 67 UU No. 
13/2003 tentang Ketenagakerjaan menegaskan bahwa pengusaha yang memperkerjakan penyandang disabilitas wajib memberikan perlindungan yang sesuai dengan tingkat kecacatannya. Meskipun sudah diatur dalam UU, hak penyandang disabilitas sampai sekarang masih sering mendapatkan perlakuan diskriminasi oleh perusahaan saat merekrut dan bahkan di tempat kerja (Shaleh, 2018).

Oleh karena itu Badan Perencanaan Pemabangunan Daerah (BAPPEDA) kabupaten Situbondo sejak tahun 2017 berinisiatif melakukan pendataan kemiskinan melalui proses Analisa Kemiskinan Partisipatif atau AKP (Bappeda, 2018a)

Usaha yang dilakukan pemerintah untuk menangani permasalahan ekonomi dan sosial difabel telah dilakukan meskipun belum maksimal. Pemerintah berusaha mengubah persepsi masyarakat tentang difabel, bahwa difabel (penyandang cacat) merupakan bagian dari masyarakat yang mempunyai kedudukan, hak, kewajiban, dan peran yang sama. Salah satu upaya pemerintah untuk meminimalisir permasalahan sosial dan ekonomi difabel di masyarakat dengan adanya LBK (Loka Bina Karya) yaitu pusat rehabilitasi bagi para difabel untuk melatih ketrampilan yang berguna bagi dunia kerja.(Setyaningsih \& Gutama, 2016)

Tujuan pendataan kemiskinan ialah untuk memeperoleh database rumah tangga atau penduduk miskin di tingkat desa yang menekankan pada pertisipasi langsung dari masyarakat desa. Mengenai validasi dan akurasi data yang dihasilkan, Bappeda secara rutin, minimal setiap tahun melakukan pembaharuan data dan proses verval. Sejak pertengahan tahun 2019, AKP berubah nama menjadi Data Tunggal Daerah- Analisa Kependudukan Partisipatif atau disingat menjadi DTD-AKP.

Dalam DTD-AKP memuat indicator pertama keberadaan anggota rumah tangga disabilitas/berkebutuhan khusus, kedua keberadaan anggota keluarga menyandang penyakit kronis/menahun. Dimana dari dua indicator tersebut ditunjukkan untuk menyerap aspirasi dan kebutuhan disabilitas di seluruh kabupaten Situbondo. Disabilitas dalam DTD-AKP didefinisikan setiap orang yang mengalami kecacatan sehingga terganggu atau mendapatkan rintangan dan hambatan baginya untuk melakukan kegiatan secara selayaknya. Kemudian berdasarkan kemampuan, disabillitas dalam DTD-AKP dibagi menjadi disabilitas produktif dan tidak produktif. Dalam arti, jika seseorang yang memiliki kecactan, tetapi fungsinya tidak terganggu masih berguna untuk bekerja minimal bagi dirinya sendiri, maka termasuk disabilitas produktif.

Turun dari indicator disabilitas dipilih kedalam ragam kedisabilitasa, yaitu tuna daksa/cacat tubuh, tuna netra, tuna rugu, tuna wicara, tuna rungu dan wicara, tuna netra dan cacat tubuh, tuna netra, rungu dan wicara, tuna rungu, wicara dan cact tubuh, tuna rungu, wicara, netra, dan cacat tubuh, cacat mental radardasi, mantan penderita gangguan jiwa, dan cact fisik dan mental. Sedangkan turun dari indicator keberadaan penyandang penyakit kronis/menehun dikhususkan kepada penderita stoke yang sudah mengalami kesulitan bergerak atau beraktivitas, sehingga menjadikan disabilitas.

Keberadaan dua indicator disabilitas dan penyandang penyakit kronis/menahun dalam DTD-AKP menunjukkan bahwa Pemerintah Kabupaten Situbondo telah memiliki inisiatif untuk memenuhi hak pendatan bagi disabilitas. Berdasrkan hasil pendataan DTD-AKP, jumlah disabilitas pada tahun 2017 ialah sebesar 11.692 jiwa, dan jumlah disabilitas pada tahun 2019 ialah sebesar 6.950 jiwa.

Apabila dibandingkan dengan penduduk Kabupaten Situbondo yang berjumlah sekitar 676.703 jiwa, maka presentase jumlah disabilitas pada tahun 2017 ialah sebesar $0,53 \%$ dari seluruh total penduduk. Angka total presentase tersebut masih masih tergolong sangat rendah apabila dibandingkan dnegan estimasi data dari Organisasi Kesehatan Dunia atau World Health Organization (WHO) yang memprediksi 15 dari 100 orang adalah disabilitas sebesar $15 \%$ dari total jumlah penduduk dan 2-4 dari 100 orang mengalami disabilitas berat.

Rendahnya angka disabilitas di Kabupaten Situbondo dapat diperkirakan karena tingginya stigma dan rendahnya kapabilitas disabilitas secara pendidikan, sehingga muncul kecendrungan disabilitas tereksklusi bahkan mengeksklusikan diri terhadap lingkungan soaial. Konsekuensinya, keberadaan mereka tidak terlihat, tersuarakan, dan tidak dimasukkan ke dalam perencanaan pembangunan. Sehingga pemerintah daerah belum 
memiliki kebijakan alokasi anggaran, minimnya pemahakan tentang konsep inklusi, dan lemahnya aspek kelembagaan ini ialah kurangnya koordinasi lintas sector, pemantauan, dan evaluasi terhadap program Kabupaten Situbondo inklusi ramah disabilitas. Apabila persoalan kelembagaan tidak segera diatasi, maka dikemudian hari akan muncul situasi program inklusi berjalan ditempat atau hilang begitu saja.

Oleh karena itu, kajian tentang penyususnan data disabilitas mengevaluasi pemenuhak hak disabilitas dalam rangka penguatan kelembagaan pembangunan inklusif di Kabupaten Situbondo perlu untuk dilaksankan. Diperlukan sebuah analisis situasi tentang kondisi, permasalahan, aspirasi, dan kebutuhan disabilitas berbasis data yang akurat dan dapat dipertanggung jawabkan, sehingga bias memunculkan langkah-langkah startegis dalam menyususn kebijakan, program, dan kegiatan yang terukur dan terintegrasi.

\section{TINJAUAN PUSTAKA}

Setiap orang terlahir dengan memiliki kelebihan dan kekurangan masing-masing. Kekurangan setiap manusia baik secara fisik maupun non fisik yang dinilai tidak normal disebut dengan istilah penyandang cacat. Seperti dalam Kamus Besar Bahasa Indonesia kata cacat sendiri adalah kekurangan yang menyebabkan nilai atau mutunya kurang baik atau kurang sempurna (yang terdapat pada badan, benda, batin, atau akhlak). Dalam Majalah Kentingan Edisi September 2011 disebutkan bahwa pada tahun 1999, istilah "penyandang cacat" diganti dengan kata "difabel" (Different Ability). Penggantian istilah ini dimaksudkan untuk memberikan makna yang lebih halus serta lebih memanusiakan kaum berkebutuhan khusus. Dengan istilah difabel, masyarakat diajak untuk merekonstruksi nilai-nilai sebelumnya yang semula memandang kondisi cacat atau tidak normal sebagai kekurangan atau ketidakmampuan menjadi pemahaman terhadap difabel sebagai manusia dengan kondisi fisik yang berbeda (Setyaningsih \& Gutama, 2016).

Orang dengan disabilitas individu/kelompok masyarakat yang termajinalkan dan rentetan. Mereka kerapkali mengalami ekslusi soal dan diskriminasi terhadap akses kehidupan dan penghidupannya. Hal tersebut dikarenakan adanya perbedaan secara pandang (perspektif) terhadap disabilitas. Setidaknya terdapat lima (5) cara pandang terhadap disabilitas, yaitu berdasarkan moral, belas kasihan, kesehatan, social, dan hak asasi manusia (Hastuti et al., 2019).

Cara padang moral, belas kasihan, dan kesehatan menfokuskan pada keterbatasan yang dimiliki individu diabilitas. Perspektif moral menganggap disabilitas sebagai kutukan/hukuman kepada keluarga/individu atas perbuatannya yang melanggar moral dalam kehidupan. Perspektif belas kasihan menggapa disabilitas sebagai individu yang tidak mampu melakukan secara mandiri sehingga perlu bantuan orang lain dan perlu dikasihani. Perspektif kesehatan menganggap disabilitas sebagai individu yang 'tidak moral' dari sisi kesehatan sehingga harus diperbaiki /diobati agar mampu menyesuaikan diri dengan lingkungannya. Cara pandang atau stigma inilah yang kemudian membentuk mengkonstruksi alam piker masyarakat bahwa disabilitas hanyalah beban ditengah tengah kehidupan bermasyarakat.

Kemudian, cara pandang berikutnya ialah social dan hak asasi manusia yang menfokuskan pada kesadaran umum masyarakat,lingkungan, dan institusi yang berperan membentuk disabilitas. Perspektif social menggangap masyarakat/lingkungan memiliki peran dalam menciptkan kondisi disabilitas bagi seseorang yang mengalami keterbatasan fisik,mental,intelektual,dan sensorik. Sedangkan perspektif hak asasi manusia mengaku keberadaan disabilitas sebagai dari keberagaman dalam masyarakat dan mengakui bahwa disabilitas memiliki hak yang sama dengan masyarakat non disabilitas lainnya. Kalau perspektif social berprinsip bahwa masyarakatlah yang harus berubah/diubah agar mampu agar mampu menyesuaikan dengan disabilitas. Sedangkan prinsip dalam perspektif hak asasi manusia adalah lebih pada pemenuhan hak disabilitas sebagai solusi atau jaminan individu yang mengalami keterbatasan fisik,mental,intelektual,dan sensosrik agar tidak mengalami eksklusi sosial.

Ekslusi sosial memiliki beberapa karakteristik, di antaranya 1) bersifat multimediasonal (terjadi pada banyak aspek kehidupan); 2) dinamis (bukanlah kondisi statis yang dialami 
kelompok yang sama dengan pola yang sama sepanjang waktu); 3) multilevel (terjadi diseluruh lini kehidupan); 4) sangat bergantung pada konteks; 5) dapat terjadi di tingkat kelompok maupun individu;dan 7) dapat pula terjadi karena kondisi kerentanan yang dimiliki individu dengan sejumlah faktor pemicu, seperti faktor struktual,perilaku,dan kebijakan.

Konsep ekslusi sosial pertama kali dikenalkan oleh Rane Lenoir, sekretaris Negara untuk uurusan aksi sosial pada pemerintahn prancis pada tahun 1970an (Syahra, 2010). Lenoir menawarkan sebuah paradigma baru untu memahami deprivisi (kesengajaan/ketidakadilan)dan kemiskinan pada kelompok/individu dalam masyarakat. Melihat permasalahan kemiskinan bukan sebagai suatu kondisi sosial, tetapi lebih dari factor factor apa saja yang telah berkontribusi terhadap proses deprevisidan kemiskinan.salah satu analisa yang dibuat oleh lenior bahwa diprancis, diantara sepuluh orang prancis mengalami eeksklusi sosial, diantaranya kelompok/individu disabilitas, orang tua jompo, anak anak salah satu perlakuan (abused),pengguna narkoba ,anak anak nakal, orang tua tunggal,keluarga bermasalah,kaum marjinal,orang orang asocial, serta orang orang yang tidak di terima dalam pergaulan masyarakat.

Eksklusi juga memiliki makna ganda, multidimensi,dan memiliki kaitan luas, sehingga setiap orang dari latar belakang ekonomi,sosial,politik, dan budaya yang berbeda bias mendefinisikannya secara berbeda pula. Akan tetapi kesulitan mendefinisikannya dan kenyataan bahwa adanya definisi yang fleksibel dalam konteks sosial,budaya,politik,dan ekonomi yang berbeda malah semakin menguntungkan dalam penggunaan sebuah teori.

Wacana eksklusi bisa digunakan sebagai pintu masuk seseorang agar bias melihat hubungan antara budaya politik dan masalah kemiskinan yang berbeda antara satu Negara dengan Negara lain. Dengan menggunakan perspektif ini pengertian yang beragam dari konsep tersebut tidaklah menimbulkan masalah ,tetapijustru merupakan sifat yang inheren dari sebuah konsep yang berbeda dalam tahap perkembangan.

Eksklusi sosial bagi disabilitas merupakan proses yang kompleks meliputi keterbatasan dalam mengakses sumber budaya,hak,pelayanan public, serta ketidak mampuan untuk berpartisipasi dalam aktivitas dan hubungan sosial yang normal (Levitas, 2005) Berbagai akses hanya tersedia bagi masyarakat kelompok non disabilitas yang kemudian mempemgaruhi kualitas hidup ,kesetaraan,dan kohesi masyarakat secara keseluruhan. Kesannya kelomok non disabilitas sebagai kelompok dominan yanga berada pada posisi struktual masyarakat tidak hanya membatasi akses, bahkan mencabut dan menghilangkan hak dari kelom minoritas (disabilitas). Eksklusi sosial disabilitas dapat digambarkan sebagai partisipasi sosial yang tidak memadai,kurang terintegrasi, dan kurangnya kemampuan (power) (Rohman, 2019)

Secara historis, disabilitas menghadapi hambatan baik struktual maupun sosial yang mengeksklusikan mereka dalam berbagai akses publik (Tobias \& Mukhopadhyay, 2017). Dari aspek kultur, disabilitas dianggap sebagai sifat fisik atau mental yang melekat dari seseorang dari pada status kapabilitasnya. Stigma menjadi hambatan kultur yang dihadapi disabilitas dalam mengakses hak haknya. Stigma yang ada di masyarakat terus diproduksi dan menjadi landasan institusi dalam mengambil keputusan. Hal ini kemudian disebut dsebagai stigma struktual. Stigma struktual merupakan stigma yang dipengaruhi oleh institusi sosial dimana tempat individu tinggal. Institusi sosial, hokum, dan kebijakan bukan hanya untuk menanamkan kepatuhan, tetapi juga mampu memproduksi dan melegitimasi diskriminasi, stereotip, dan sikap negatif. Melalui pemhaman terhadap konsep eksklusi sosial dilevel kultur dan level struktual, penelitan ini diharapkan dapat memotret eksklusi sosial untuk menciptakan kebijakan pembangunan inklusif.

Kebijakan pembangunan inklusif dapat dipilah dari makna pembngunan dan inklusif. Pembangunan merupakan proses untu mendorong perbaikan kesejahteraan masyarakat dalam arti luas tidak hanya dari sisi ekonomi, tetapi juga dari sisi sosial,politik, dan kesehatan (Kanbur \& Rauniyar, 2010). Sementara inklusif bermakna kondisi yang memastikan adanya keterlibatan seluruh pihak secara bermakna (tanpa diskriminasi) dan keterlibatan ini bukan sekedar keterlibatan untuk menghidari konflik, sehingga membuat inividu/kelompok memiliki rasa kepemilikan dan motivasi untuk berkontribusi (From \& Katz, 2002). Inklusi ini merupakan 
berkebalikan dari kondisi eksklusi. Dengan mengkomodasi arti kedua kata tersebut ,pembangunan inklusif dapat diartikan sebagi proses pembangunan yang memastikan keterlibatan seluruh kelompok, termasuk marginal,dalam proses pembangunan, disertai adanya rasa memiliki dari setiap elemen masyarakat terhadap proses pembangunan (Pierce, 2014).

\section{METODOLOGI PENELITIAN}

Kajiana ini dilakukan secara kualitatif dengan menggunakan informasi melalui studi pustaka, dan telaah data disabilitas dalam Data Tunggal Daerah-Analisa Kependudukan Partisipatif (DTD-AKP). Data disabilitas dipilah berdasarkan indicator dalam pendataan DTDAKP untuk memunculkan kondisi disabilitas secara komprehensif. Setelah melakukan pengamatan dan telaah terhadap data disabilitas, kemudian dilakukan penelusuran pustaka berupa peraturan, kebijakan, dan program serta refrensi lain yang berhubungan dengan analisis situasi disabilitas. Selanjutnya dilakukan diskusi kelompok terfokus bersama Badan Perencanaan Pembangunan Daerah (Bappeda) dan OPD lintas sector, dan akademisi untuk menggali informasi mengenai kebijakan, program, dan kegiatan yang sudah dilakukan untuk semakin memperkuat kelembagaan Situbondo inklusi ramah disabilitas.

Pelaksanaan analisis situasi disabilitas dikuatkan melalui kajian tentang eksklusi sosial yang dialami oleh disabillitas berdasrkan hasil telaah data disabilitas. Kemudian, dari hasil analisis situasi dikerucutkan agar lebih mengarah pada rekomendasi tentang strategi pembuatan kebijakan, program, dan kegiatan untuk penguatan kelembagaan Situbondoinklusi ramah disabilitas.

\section{HASIL PEMBAHASAN}

\section{Jumlah dan Indikator Data Disabilitas}

Berdasarkan Data Tunggal Daerah-Analisa Kependudukan Partisipatif (DTD-AKP) Kabupaten Situbondo, disabilitas dibagi kedalam 13 ragam disabilitas. Jumlah disabilitas pada tahun 2018 ialah 11.770 jiwa atau 1,71\% dari jumlah total penduduk situbondo sebesar 678.099 jiwa. Dari data tersebut disabilitas usia 0-4 tahun (balita) sekitar 3\%. Disabilitas usia 5-17 (anak) sekitar 13\%. Disabilitas usia 18-59 (usia produktif angkatan kerja) sekitar 50\%. Disabilitas usia diatas 60 tahun (lansia) sekitar 34\%. Diatara pembagian usia tersebut proporsi terbesar ditemukan pada usia produktif angkatan kerja sebanyak $50 \%$ dari total data keseluruhan data disabilitas di Kabupaten Situbondo.

Tabel 1

Analisa Kependudukan Partisipatif (DTD-AKP) Kabupaten Situbondo

\begin{tabular}{llccccc}
\hline No & Ragam Disabilitas & $\begin{array}{c}\text { Disabilitas } \\
\text { Usia 0-4 } \\
\text { Tahun }\end{array}$ & $\begin{array}{c}\text { Disabilitas } \\
\text { Usia 5-17 } \\
\text { Tahun }\end{array}$ & $\begin{array}{c}\text { Disabilitas } \\
\text { Usia 18- } \\
59 \text { Tahun }\end{array}$ & $\begin{array}{c}\text { Disabilitas } \\
\text { Usia 60 } \\
\text { Thn keatas }\end{array}$ & Jumlah \\
\hline 1 & 34 & 145 & 812 & 2369 & 3360 \\
\hline $\begin{array}{l}\text { Tuna Daksa / Cacat } \\
\text { Tubuh }\end{array}$ & Tuna Netra / Buta & 274 & 1164 & 4103 & 1085 & 6626 \\
\hline 3 & Tuna Rungu & 2 & 16 & 114 & 212 & 344 \\
\hline 4 & Tuna Wicara & 25 & 102 & 365 & 117 & 609 \\
\hline 5 & $\begin{array}{l}\text { Tuna Rungu dan } \\
\text { Wicara }\end{array}$ & 4 & 17 & 73 & 17 & 111 \\
\hline 6 & $\begin{array}{l}\text { Tuna Netra dan } \\
\text { cacat Tubuh }\end{array}$ & 1 & 4 & 42 & 8 & 55 \\
\hline 7 & $\begin{array}{l}\text { Tuna Netra, Rungu, } \\
\text { dan Wicara }\end{array}$ & 0 & 4 & 18 & 10 & 32 \\
\hline $\begin{array}{l}\text { Tuna Rungu, } \\
\text { Wicara, dan Cacat } \\
\text { Tubuh }\end{array}$ & 1 & 11 & 25 & 9 & 46 \\
\hline
\end{tabular}




\begin{tabular}{clccccc}
\hline No & Ragam Disabilitas & $\begin{array}{c}\text { Disabilitas } \\
\text { Usia 0-4 } \\
\text { Tahun }\end{array}$ & $\begin{array}{c}\text { Disabilitas } \\
\text { Usia 5-17 } \\
\text { Tahun }\end{array}$ & $\begin{array}{c}\text { Disabilitas } \\
\text { Usia 18- } \\
59 \text { Tahun }\end{array}$ & $\begin{array}{c}\text { Disabilitas } \\
\text { Usia 60 } \\
\text { Thn keatas }\end{array}$ & Jumlah \\
\hline $\begin{array}{l}\text { Tuna Rungu, } \\
\text { Wicara, Netra, dan } \\
\text { Cacat Tubuh }\end{array}$ & 0 & 5 & 33 & 15 & 53 \\
\hline 10 & $\begin{array}{l}\text { Cacat Mental dan } \\
\text { Retaldasi }\end{array}$ & 0 & 31 & 140 & 33 & 204 \\
\hline 11 & $\begin{array}{l}\text { Mantan Penderita } \\
\text { Gangguan Jiwa }\end{array}$ & 0 & 1 & 35 & 9 & 45 \\
\hline 12 & $\begin{array}{l}\text { Cacat Fisik dan } \\
\text { Mental }\end{array}$ & 2 & 34 & 117 & 54 & 207 \\
\hline 13 & Stroke & 0 & 4 & 49 & 25 & 78 \\
\hline & JUMLAH & 343 & 1538 & 5926 & 3963 & 11770 \\
\hline
\end{tabular}

Disabilitas adalah kelompok yang memiliki ketentanan. Dari data diatas disabilitas tunggal sebanyak 11.017 jiwa atau $94 \%$ dan disabilitas multi sebangayak 753 orang atau $6 \%$ distribusi tingkat keparahan ini cenderung sama antar tingkat usia.

\section{Analisis Situasi Disabilitas Berbasis Data}

\section{a. Disabilitas Usia 5-17 (Anak)}

Usia 5-17 merupakan usia wajib belajar. Sebenarnya Indonesia mulai mengupayakan pendidikan inklusi sejak dikeluarkannya Surat Edaran Dirjen Dikdasmen Depdiknas No.380/C.C6/MN/2003 pada 20 Januari 2003 kemudian diperkuat dengan dikeluarkannya Permendiknas No. 70 tahun 2009 tentang Pendidikan Inklusi bagi peserta didik yang memiliki kelainan dan memiliki potensi kecerdasan dan/atau bakat istimewa. Hal ini memang sejalan dengan hasil kesepakatan Konferensi Dunia di Salamanca pada tahun 1994 dan Deklarasi Dakar tahun 2000 yang berupaya mengakomodasi kebutuhan dasar masya-rakat tentang pendidikan untuk semua (Education for All) tanpa memandang ras, agama dan potensi peserta didik (Lukitasari et al., 2017). Pendidikan merupakan hak bagi setiap warga Negara. Anak dengan disabilitas atau Anak bekebutuhan Khusus (ABK) memiliki hambatan dalam mengakses pendidikan. Terlihat pada data disabilitas usia wajib belajar ialah sebanyak $18 \%$ anak disabilitas yang tidak/belum pernah sekolah, $10 \%$ anak disabilitas sudah tidak sekolah lagi. Dan $72 \%$ masih sekolah.

Saat ini ketersediaan sekolah bagi anak disabilitas ada dua pilihan, yaitu Sekolah Luar Biasa (SLB) dan sekolah inklusi. Ketersediaan SLB di Kabupaten Situbondomasih terdapat dua sekolah, yang bertempat di wilahayah Patokan (Wilayah Tengah) dan Wilayah Suboh (Wilayah Barat). Sementara itu, ketersediaan SLB diwilayah Kecamatan Banyuputih, Asembagus, Jangjar, Arjasa, Kapongan (Wilayah Timur) masih bekum tersedia. Kemudian masalah yang ,muncul ialah jauhnya akses terhadap sarana pendidikan dan ketidakmampuan orang tua mengantar. Dua hal tersebut mengakibatkan tingginya anak dengan disabilitas tidak/belum pernah sekolah ini masih tinggi dan tergolong banyak.

Sejak adanya program Peduli Pilar Disabilitas yang dilaksanakan oleh Pelopor Peduli Disabilitas Situbondo (PPDiS) bersama Pemerintah Kabupaten Situbondo telah menginisiasi pilot project pemebentukan sekolah inklusi di SDN 4 Kalisari, Kecamatan Panarukan. Idealnya, sekolah inklusi tidak hanya mengintegrasikan keberadaan siswa disabilitas dan non-disabilitas disekolah yang sama, tetapi juga memeberikan desain pembelajatan/sarana prasarana yang ramah terhadap anak disabilitas. Karena akses sebaran SLB dan sekolah inklusi di situbondo sebaranya masih belum merata di setiap kecamatan. Oleh karena itu, diperlukan inisiatai dari pemerintah daerahuntuk membentuk sekolah inklusi disetiap kecamatan agar anak dengan disabilitas bias mendapatkan kesempatamn yang sama dengan anak yamng non-disabilitas dalam mengakses pendidikan. 


\section{b. Disabilitas Usia 18-59 (Usia Produktif dalam Angkatan Kerja)}

Tingginya angka usia produktif dalam angkatan kerjan ialah sebesar 5.926 jiwa atau $50 \%$ dari jumlah total disabilitas yang ada di Kabupaten Situbondo. Hal ini merupakan peluang besar bagi disabilitas untuk masukdalam pasar tenaga kerja produktif.

Dari status pekerhjaan, terdapat $14 \%$ disabilitas yang memiliki usaha mandiri (wiraswasta), 33\% sebagai Buruh/karyawan/pegawai swasta, 2\% sebagai PNS/TNI/Polri/BUMN/BUMD/ Anggota DPR, 7\% sebagai pekerja bebas pertanian, 2\% sebagai pekerja bebas non-pertanian, dan $42 \%$ pekerja keluarga tidak dibayar atau tidak mendapat upah.

Tingginya data usia produktif dalam angkatan kerja sementara ialah $42 \%$ disabilitas sebagai pekerja keluarga tidak dibayar atau tidak mendapatkan penghasilan. Keberadaan disabilitas yang tidak memiliki penghasilan dalam hal ekonomi masih tergantung pada orang lain/keluarga untuk menyambung hidupnya.

Dari pembacaan data diatas menuntut pemerintah daerah bersama masyarakat untuk terus menupayakan agar disabilitas dalam usia produktif angkatan kerja bias mendapatkan kesempatan yang sama dalam mengkses pekerjaan dan peluang memiliki usah sendiri, sesuai dengan hak disabilitas untuk dapat hidup secara mandiri. Secara ekonomi para difabel juga mengalami peningkatan pendapatan meskipun peningkatan tidak siginifikan pada bertambahnya jumlah materi yang didapatkan namun para difabel dibekali dengan soft skill yang baru dan lebih terampil. Beberapa informan juga memiliki usaha baru dengan berwirausaha atau mendapatkan mata pencaharian baru. Sehingga secara langsung difabel tidak lagi menggantungkan kebutuhan ekononmi kepada orang lain terutama kepada keluarganya sendiri. Pola-pola kemandirian secara ekonomi telah menunjukkan perkembangan yang besar pada perubahan diri difabel dan pola tersebut terpelihara dengan baik. (Setyaningsih \& Gutama, 2016)

Diatara disabilitas yang bekerja, $33 \%$ disabilitas berja sebagai buruh/karyawan/pegawai swasta menyerap lebih banyak dalam bekerja. Untuk menambah kesempatan yang lebih besar bagi disabilitas dalam pekerjaan perlu adanya kebijakan daerah sesuai dengan amanat Undang-Undang Disabilitas Nomor 8 Tahun 2016 ialah agar perusahaan swasta bias menyerap 1\% dari jumlah total pekerja untuk memperkerjakan disabilitas dalam perusahaannya. Presentase tersebut merupakan kuota untuk memperluas peluang disabilitas bekerja dalamsektor swasta.

Disabilitas yang berirausaha atau memiliki usaha sendiri terdapat sekitar $14 \%$. Berwirausaha akhirnya menjadi pilihan banyak penyandang disabilitas di Situbondo. Bagi mereka yang berwirausaha terdapat kendala tambahan, yaitu keterampilan dan pendanaanj. Keberadaan lembaga pemerintah dan non-pemerintah yang menyediakan pelatihan keterampilan bagi penyandang disabilitas sangt terbatas dan pelaksanaanya tidak rutin.

\section{c. Disabilitas usia diatas 60 Tahun (Lansia)}

Pesentase disabilitas usia 60 Tahun atau disabilitas Lansia 34\% dari jumlah total disabilitas yang berada di Kbupaten Situbondo, disabilitas memiliki kerentenan sendiri dalam hal mobilitas tambahan sebagai Lansis, dalam hal ini disabilitas lansia memiliki kerentenan yang parah dalam hal mobilitas dan kesehatan, dari data jumlah disabilitas lansia sebanyak 59\% Disabilitas yang memiliki penyakit kronis menahun.

Dalam hal mobilitas dan kesehatan disabilitas lansia ialah1.636 jiwa atau sekitar $70 \%$ yang memiliki penyakit kronis/menahun, tidak memiliki jaminan sosial kesehatan. Keberadaan disabilitas lansia yang memiliki penyakit kronis/menahun serta yang memiliki jaminan sosial kesehatan harus menjadi perhatian secara khusus oleh pemerintah daerah agar disabilitas lansia tidak terekskusi dari layanan kesehatan. 


\section{Peraturan Daerah Nomor 3 Tahun 2018 tentang Perlindungan dan Pemberdayaan Penyandang Disabilitas}

Pemerintah Kabupaten Situbondo telah menerbitkan Peraturan Daerah Nomor 3 Tahun 2018 tentang Perlindungan dan Pemberdayaan Penyandang Disabilitas. Pewrda ini merupakan inisiatif dari Dewan Perwakilan Daerah (DPRD) Kabupaten Situbondo.

Dasar pertimbangan diterbitkannya perda ini ialah menyadari bahwa disabilitas memiliki kedudukan, hak, keawajiban, dan peran yang sama dengan lainnya di segala aspek kehidupan dan penghidupan. Untuk mewujudkannya diperlukan akses, sarana, dan upaya yang lebih memadai, terpadu, terpadu, dan berkesinambungan sehingga terwujud perlindungan, kemandirian, dan kesejahteraan disabilitas tanpa diskriminasi. Maka, untuk terlaksananya perlindungan dan pemberdayaan disabilitas diperlukan jaminan perlindungan dan hak-hak disabi;litas yang merupakan tanggung jawab pemerintah, pemerintah daerah, dan masyarakat.

Definisi perlindungan yang dimaksud ialah upaya yang dilakukan secara sadar untuk melindungi, mengayomi, dan memperkuat hak disabilitas. Sedangkan definisi pemberdayaan ialah upaya untuk menguatkan keberadaan disabilitas dalam bentuk perubahan iklim dan pengembangan potensi sehingga mampu tumbuh dan berkembang menjadi individu atau kelompok disabilitas yang tangguh dan mandiri. Adapun tujuan penyelenggaraan perlindungan dan pemberdayaan disabilitas ialah untuk meningkatkan taraf kesejahteraan, kualitas dan kelangsungan hidup, memulihkan fungsi sosial dan kemapuan disabilitas dalam rangka mencapai kemandirian, meningkatkan kemampuan, kepedulian, dan tanggung jawab sosial pemerintas daerah dan dunia usaha dalam menyelenggarakan perlindungan dan pemberdayaan disabilitas, dan meningkatkan kepedulian masyarakat dalam berinteraksi atau bersosialisasi dengan disabillitas.

Dalam Perda 3/2018 terdapat 22 hak disabilitas diantaranya hak hidup, bebas dari stigma, privasi, keadilan dan perlindungan hokum, pendidikan, pekerjaan, kewirausahaan, dan koperasi, kesehatan, politik, keagamaan, keolahragaan, kebudayaan dan pariwisata, kesejahteraan sosial, aksesibilitas, pelayanan public, perlindungan bencana, habilitasi dan rehabilitasi, konsensi, pendataan, hidup dalam mandiri dan dilibatkan dalam masyarakat, berekspresi, berkomunikasi, dan memperoleh insormasi, berpindah tempat dan kewarganegaraan, dan bebas dari tindakan diskriminasi, penelantaraan, menyiksa dan eksploitasi.

Dari 22 hak tersebut, untuk disabilitas perempuan ditambah empat hak lagi yaitu ha katas kesehatan reproduksi, menerima atau menolak penggunaan alat kontrasepsi, mendapatkan perlindungan lebih dari erlakuan diskriminasi berlapis, dan untuk mendapatkan perlindungan lebih dari tindakan kekerasan, termasuk kekerasan dan eksploitasi seksual. Sedangkan untuk anak disabilitas ditambah tujuh hak lagi yaitu, hak mendapat perlindungan khusus dari diskriminasi, penelantaran, pelecehan, serta kekerasan, dan kejahatan seksual, mendapatkan perawatan dan pengasuhan darin keluarga dan keluarga pengganti untuk tumbuh kembang secara optimal, dilindungi kepentingannya dalam pengambilan keputusan, perlakuan anak secara manusiawi sesuai dengan martabat dan hak-hak anak, pemenuhan kebutuhan khusus, perlakuan yang sama dengan anak lain untuk mencapai integrasi sosial dan pengembangan individu, dan mendapat pendampingan sosial.

Berdasarkan jenis pelaksanaan perlindungan dan pemberdayaan disabilitas ada dua jenis yaitu, pertama jenis perlindungan penyandang disabilitas yang diberikan ialah rehabilitas, medic, rehabilitas sosial, bantuan sosial, dan pendidikan, kedua pemberdayaan penyandang disabilitas dilakukan melalui peningkatan kemauan dan kemampuan, pemberian bantuan usaha dan pemberian akses, serta diagonis dan pemberian motivasi, pelatihan keterampilan, pemberian stimulant modal, peralatan usaha dan tempat usaha serta peningkatan akses pemasaran hasil usaha. 


\section{Peta Jalan (roadmap) Situbondo Menuju Kabupaten Inklusif ramah Disabilitas Tahun 2018-2022}

Peta jalan (roadmap) Situbondo Menuju Kabupaten Inklusif Ramah DIsabilitas Tahun 2018-2022 dibuat atas inisiatif Program Situbondo Inklusi Terintegrasi (SINERGI) antara organisasi Pelopor Peduli Disabilitas Situbondo (PPDiS) dan Pemerintah Kabupaten Situbondo, dalam hal ini Bada Perencanaan Pembangunan daerah (Bappeda, 2018b)

Visi yang ingin dicapai ialah Situbondo Menjadi Kabupaten Inklusif Ramah DIsabilitas. Sedangkan misinya ialah 1. Meningkatkan inisiatif, sinergi, dan inovasi pemerintah kabupaten, baik eksekutif, legislative, dan yudikatif dalm perlindungan dan pemberdayaan disabilitas dan seluruh masyarakat. 2. Pelibatan disabilitas, baik organisasi atau individu, secara aktif dan bermakna dalam kebijakan pembangunan. 3. Merangkul masyarakat agar menerima, peduli, dan ikut menciptakan lingkungan yang inklusif ramah disabilitas.

Dari beberapa capaian dalam program SINERGI, yang paling strategis ialah diterbitkan dokumen "Peta Jalan (roadmap) Situbondo Menuju Kabupaten Inklusi Ramah Disabilitas Tahun 2018-2022". Dokumen tersebut merupakan panduan bangunan bagi Pemerintah kabupaten Situbondo dalam upaya memberdayakan, melindungi, memenuhi, dan persoatif terhadap hak-hak disabilitas. Dalam dokumenpeta jalan memuat delapan 8 sektor penting untuk memenuhi kriteria sebagai kabupaten inklusif ramah disabilitas. Kriteria tersebut merujuk padfa Instrumen Penilaian Kota Inklusif yang diterbitkan UNESCO tahun 2017 yang bekerja sama dengan Asosiasi Pemerintah Kota Indonesia (APEKSI). Instrument yang sudah ditetapkan oleh APEKSI sebanyan sebelas 11 sektor, kemudian dimodifikasi dan disesuaikan dengan konteks Kabupaten Situbondo, sehingga menjadi delapan 8 sektor.

Delapans ektor tersebut ialah. Data, pengembangan Masyarakat, pemenuhan Hak disabilitas, kesehatan, pendidikan, keagamaan, pekerjaan dan kewirausahaan, dan pemenuhan hak keadilan dan perlindungan. Dari delapan sector tersebut dijabarkan kedalam program, indicator program, OPD/lembaga pengampu, dan target atau rencana perealisasiannya pertahun dari 2018-2022.

\section{DTD-AKP dan Data Disabilitas}

Persoalan pertama dalam mengadvokasi isu disabilitas ialah pendataan. Pihak-pihak penyelenggara pendataan memuliki beragam devinisi tentang disabilitas sehingga hasil pendataannya pun juga beragam, disesuaikan dengan peruntukannya. Tidak ada data tunggal ynag lebin rugid dalam memotret persoalan disabilitas dari berbagai sudut pandang. Akhirnya data yang dihasilkan relative belum bias menggambarkan kondisi nyta kehidupan dan penghidupan disabilitas.

Namun, dikabupaten Situbondo, sejak tahun 2017 seudah menginisiasi proses pendataan disabilitas melalui Analisa Kemiskinan Partisipatif (AKP), yang dikemudian hari berganti menjadi Data Tunggak Daerah-Analisa kependudukan Partisipatif DTD-AKP. Penuyusunan dat induk disabilitas berbasis nama dan alamat (by name by address) yang memuat semua informasi kependudukan. Pelaksanaanya pun dilakukan dari bawah keatas (buttom up), mulai dari tingkat desa, kecamatan, dan kabupaten. Dilakukan secara pertisipatif oleh penduduk dan aparat desa untuk menetukan indicator-indikator yang sesuai dengan kondisi sosial budaya masyarakat.

Proses penentuan indicator dan program kegiatan pendataan didasarkan pada kondisi wilayah geografis pada tingkat kecamatan yang dikenal dengan klaster. Klaster adalah pengelompokan wilayah kecamatan berdasarkan kondisi topografis, letag geografis, mata pencarian, dan kondisi ekonomi sosial budaya. Dari 17 kecamatan di Kabupaten Situbondodipilah kedalam empat 4 klaster, yaitu klaster pegunungan, pesisir, perkotaan, dan klaster antara.

Variable dan kriteria penduduk miskin daerah yang ada di Kabupaten Situbondo ini disesuaikan dengan 61 indikator. Terdapat dua indicator yang mana berhubungan dnegan disabilitas, yaitu indicator ke 60 tentang "ada anggota rumah tangga disabilitas/berkebutuhan khusus" dan indicator ke 61 tentang "ada anggota rumah tangga 
menyandang penyakit kronis/menahun". Untuk indicator 61, yang dapat dimasukkan kedalam ragam disbilitas ialah orang dengan penyakit stroke.

Keberadaan dua indicator disabilitas dan penyandang penyakit kronis/menahun dalam DTD-AKP menunjukkan bahwa Pemerintah Kabupaten Situbondotelah memiliki inisiatif untuk memenuhi hak pendataan bagi disabilitas pada tahun 2017 ialah sebesar 3.163 jiwa, jumlah disabilitas pada tahun 2018 ialah sebesar 11.692 jiwa, dan jumlah disabilitas pada tahun 2019 ialah sebesar 6.950 jiwa.

Naik turunnya jumlah penyandang disabilitas dalam DTD-AKP dapat dikarenakan bebrapa persoalan, yaitu Pertama pendata ditingkat desa belum memahami secara utuh tentang konsep kedisabilitasan, kedua tertutupnya keluarga disabilitas terhadap pendata dikarenakan stigma, ketiga stigma bahwa disabilitas tidak perlu didata karena tidak aka nada gunanya untuk diri disabilitas, keempat disabilitas bereksklusi dan mengeksklusikan diri, dan kelima belum ada program pemerintah yang memliki manfaat langsung terdapat disabilitas setelah dilakukan pendataan.

Oleh karena itu, melalui Program SINERGI, Bappeda Kbupaten Situbondo melibatkan organisasi PPDiS untuk melakukan verivikasi dan validasi (verval) data disabilitas dalam DTD-AKP tahun 2019. Pendekatan sejawat (sesame disabilitas) dengan kebutuhan nyata disabilitas di Kabupaten Situbondo. Harapan kedepan, data disabilitas dalam DTD-AKP akan semakin baik dan meningkat agar setiap kebijakan, program, kegiatan, dan layanan pemerintah bias bias tepat sasaran dan bermanfaat langsung bagi penyandang disabilitas.

\section{PENUTUP dan KESIMPULAN}

Berdasarkan data disabilitas dalam DTD-AKP tahun 2018 dapat diketahi bahwa kondisis disabilitas masih mengalami eksklusi sosial. Beberapa diantaranya persoalan kondisi disabilitas, kesehatan, kesempatan dalam pekerjanan, dan kepemilikan Kartu Kesejahteraan Keluatga (KKS) yang merupakan hak dasar yang seharusnya mereka terima. Namun, sebagian besar dari mereka belum menerima haknya secara utuh. Dari hal itu yang terjadi semua berakibat terhadap keadaan perekonomian sehari-hari dimana setiap kaum penyandang disabilitas tidak mandiri dan bergantung kepada orang tua, jika semuanya terpenuhi dari pekerjaan dan lain-lain kemungkinan besar para kaum difabel akan mandiri dan tidak bergantung kepada orang lain terutama orang tuanya. Oleh karena itu, diperluka penguatan kelembagaan yang multisektor untuk mengatsi eksklusi sosial, sehingga setiap kebijakan, program, kegiatan, dan layanan yang dilakukan Pemerintah Kabupaten Situbondo bisa benar-benar inklusi terhadap kelompok/individu disabilitas.

\section{DAFTAR PUSTAKA}

Bappeda. (2018a). Pedoman Pendataan Penduduk Miskin Partisipatif Kabupaten Situbondo. (Situbondo (ed.)). AKP.

Bappeda. (2018b). Peta Jalan Situbondo Menuju Kabupaten Inklusi Ramah Disabilitas tahun 2018-2022 (Situbondo (ed.)). SINERGI.

From, A. E., \& Katz, J. H. (2002). The inclusion breakthrough: unleashing the real power of diversity. Choice Reviews Online, 40(04), 40-2262-40-2262.

https://doi.org/10.5860/choice.40-2262

Hastuti, Dewi, R. K., Pramana, R. P., \& Sadaly, H. (2019). Kendala Mewujudkan Pembangunan Inklusif terhadap Penyandang Disabilitas Kendala MewujudkanPembangunan Inklusif terhadap Penyandang Disabilitas.

Kanbur, R., \& Rauniyar, G. (2010). Conceptualizing inclusive development: With applications to rural infrastructure and development assistance. Journal of the Asia Pacific Economy, 15(4), 437-454. https://doi.org/10.1080/13547860.2010.516163

Levitas. (2005). The Inclusive Society. IN liberiy, equality, futernity. 
Lukitasari, S. W., Sulasmono, B. S., \& Iriani, A. (2017). Evaluasi Implementasi Kebijakan Pendidikan Inklusi. Kelola: Jurnal Manajemen Pendidikan, 4(2), 121. https://doi.org/10.24246/j.jk.2017.v4.i2.p121-134

Nuraviva, L. (2008). Aksesibilitas Penyandang Disabilitas Terhadap Fasilitas Publik Di Kota Surakarta. Journal of Medical Internet Research, 10(3), e28.

Pierce, S. D. (2014). Progress Since Busan on Inclusive Development. April.

Rohman, Y. F. (2019). Eksklusi Sosial dan Tantangan Penyandang Disabilitas Penglihatan Terhadap Akses Pekerjaan. Indonesian Journal of Religion and Society, 1(1), 51-66. https://doi.org/10.36256/ijrs.v1i1.25

Setyaningsih, R., \& Gutama, T. A. (2016). Pengembangan kemandirian bagi kaum difabel. Sosiologi DILEMA, 31(1), 42-52.

Shaleh, I. (2018). Implementasi Pemenuhan Hak bagi Penyandang Disabilitas Ketenagakerjaan di Semarang. Kanun: Jurnal IImu Hukum, 20(1), 63-82. https://doi.org/10.24815/kanun.v20i1.9829

Syahra, R. (2010). Eksklusi Sosial: Perspektif Baru Untuk Memahami Deprivasi dan Kemiskinan. Jurnal Masyarakat Dan Budaya LIPI Edisi Khusus, 12(3), 1-34.

Tobias, E. I., \& Mukhopadhyay, S. (2017). Disability and Social Exclusion: Experiences of Individuals with Visual Impairments in the Oshikoto and Oshana Regions of Namibia. Psychology and Developing Societies, 29(1), 22-43.

https://doi.org/10.1177/0971333616689203 